\title{
MICROBIAL LEACHING OF CHROMIUM FROM SOLIDIFIED WASTE FORMS - A KINETIC STUDY
}

\author{
Carmalin Sophia Ayyappan ${ }^{1}$ \\ 1 National Environmental Engineering Research Institute, CHZL, CSIR Complex, Taramani, Chennai 600113 , \\ India, e-mail: ac_sophia@neeri.res.in
}

Received: 2015.02 .18

Accepted: 2015.06.02

Published: 2015.07.01

\begin{abstract}
In this study, Thiobacillus thiooxidans (T. thiooxidans) was used to study the microbial stability / degradation of cement-based waste forms. The waste forms contained a chromium salt $\left(\mathrm{CrCl}_{3} \cdot 6 \mathrm{H}_{2} \mathrm{O}\right)$, cement and other additives viz., lime and gypsum in two different proportions. The experimental samples of all the simulated waste forms showed evidence of microbial growth as indicated by substantial increase in sulfate. Chromium leached from the waste forms was found to be lowest in cement - lime solidified waste forms $\left(0.061 \mathrm{mg} \cdot \mathrm{l}^{-1}\right)$ and highest in cement gypsum waste forms $(0.22$ $\mathrm{mg} \cdot \mathrm{l}^{-1}$ ) after 30 days of exposure. These values were lower than the toxicity characteristic leaching procedure (TCLP), regulatory limit $\left(5 \mathrm{mg} \cdot \mathrm{l}^{-1}\right)$. Model equations based on two shrinking core models (acid dissolution and bulk diffusion model), were used to analyze the kinetics of microbial degradation of cement based waste forms. The bulk diffusion model was observed to fit the data better than the acid dissolution model, as indicated by good correlation coefficients.
\end{abstract}

Keywords: Thiobacillus thiooxidans, microbial degradation, shrinking core model.

\section{INTRODUCTION}

Treatment technologies, such as coagulation/ flocculation, precipitation, ion exchange and adsorption, generate huge quantities of toxic heavy metal laden sludges. The sludges thus generated cannot be disposed of directly into the landfill, due to a risk of ground water contamination. There are no or few secure landfills to support the huge quantities of heavy metal laden sludges generated every day. Hence, it becomes important to treat the sludges before disposal to a landfill [Sophia, Swaminathan 2005].

The US Environmental Protection Agency (USEPA) recognizes cementitious solidification as the "best demonstrated available technology (BDAT)" for land disposal of toxic elements [Conner 1990]. Alkaline matrices such as $\mathrm{Ca}(\mathrm{OH})_{2}$ and cement are commonly used in waste conditioning because they are inexpensive, readily incorporate wet wastes and their alkalinity reduces the solubility of hazardous heavy metals.
Solidification/stabilization $(\mathrm{S} / \mathrm{S})$ is a process in which inorganic reagents react with certain waste components and form chemically stable solids which are capable of developing mechanical resistance. The major inorganic reagent is portland cement, which upon addition of water produces a hardened paste. This paste binds together aggregates and other substances to form concrete and stabilize wastes. This technology is currently being used to treat a wide variety of wastes containing such contaminants as metals, organics, organo-metallics, soluble salts, etc.

Solidified wastes disposed of in landfills are subject to physical, chemical and microbial attacks and should be evaluated for their stability to these conditions before disposal. Much research work has been done on studying the mechanical stability and chemical durability of the immobilized waste forms [Rossetti et al. 2002, Chong et al. 2000, Tsivilis et al. 2000, Poon, Chen 1999, Wang, Vipulanandan 2000, Chan et al. 2000]. 
Recently, testing for microbial stability of solidified/stabilized (S/S) waste has gained grounds as part of the long-term performance assessment protocol [Sophia et al. 2007]. Studies [Idachaba et al. 2002, Idachaba et al. 2003] have shown that a biological mechanism is involved for the leaching of chromium from cement waste forms. 'Thiobacillus' has been identified as a major reason in deterioration process of concrete pipeline [Mori et al. 1992, Parker 1945]. In the bioleaching process sulfuric acid is formed which attacks the cementitious matrix of the concrete causing loss of strength. T. thiooxidans was chosen in this study, as it is recognized to be the most dominant microorganism in the degradation of cement-based materials.

The aim of this study was to examine the kinetics of microbial degradation of three different immobilized synthetic waste forms. The novelty of this work is bioleaching of lime and gypsum containing solidified waste. It has not been experimented before. This study is important since the overall efficiency of the waste fixation process is directly related to how effectively the components of the binder are held in place.

\section{MATERIALS AND METHODS}

\section{Binders}

Three different binder materials viz., Portland cement, lime and gypsum were used for immobilization of metal containing waste. Portland cement - grade 43 , gypsum $\left(\mathrm{CaSO}_{4} \cdot 5 \mathrm{H}_{2} \mathrm{O}\right)$ and lime were bought from a local vendor. Major compositions of the binders are presented in Table 1 . Heavy metal concentrations were found to be negligible in the binders

Table 1. Chemical composition of the binders

\begin{tabular}{|c|c|c|c|}
\hline Chemical & Cement (\%) & Lime (\%) & Gypsum (\%) \\
\hline $\mathrm{SiO}_{2}$ & 19.0 & 0.55 & 1.28 \\
\hline $\mathrm{Al}_{2} \mathrm{O}_{3}$ & 7.2 & 0.4 & 0.30 \\
\hline $\mathrm{Fe}_{2} \mathrm{O}_{3}$ & 3.1 & 0.17 & 0.46 \\
\hline $\mathrm{CaO}$ & 62 & 53.47 & 2.5 \\
\hline $\mathrm{MgO}$ & 3.04 & 1.02 & trace \\
\hline $\mathrm{Na}_{2} \mathrm{O}$ & 0.15 & 0.02 & 0.03 \\
\hline $\mathrm{K}_{2} \mathrm{O}$ & 0.48 & 0.01 & 0.05 \\
\hline $\mathrm{SO}_{3}$ & 1.28 & - & 46.2 \\
\hline
\end{tabular}

\section{Specimen preparation}

The method is explained in authors' earlier publication [Sophia, Swaminathan 2005, Sophia et al. 2007]. The mix ratios prepared are presented in Table 2.

Table 2. Mix ratios

\begin{tabular}{|c|c|}
\hline $\mathrm{ID}$ & Ratio in parts \\
\hline $\mathrm{SL}^{*}$ & $10.26 \% \mathrm{CrCl}_{3} \cdot 6 \mathrm{H}_{2} \mathrm{O} ; 79.74 \%$ cement; $10 \%$ lime \\
\hline $\mathrm{SG}^{*}$ & $10.26 \% \mathrm{CrCl}_{3} \cdot 6 \mathrm{H}_{2} \mathrm{O} ; 79.74 \%$ cement; $10 \%$ gypsum \\
\hline
\end{tabular}

* Control samples (SL, SG) for each mix were made without chromium salt.

\section{Microorganism and bioleaching experiments}

The microorganism used in this study, T. thiooxidans. It was obtained from IMTECH, Chandighar, India. The microorganism was grown using a medium consisting of the following $(\mathrm{g} / \mathrm{L})$ : $\mathrm{MgSO}_{4} \cdot 6 \mathrm{H}_{2} \mathrm{O}(0.4),\left(\mathrm{NH}_{4}\right)_{2} \mathrm{SO}_{4}(0.5), \mathrm{CaCl}_{2}(0.1)$, $\mathrm{FeSO}_{4}(0.01), \mathrm{K}_{2} \mathrm{~S}_{4} \mathrm{O}_{6}(3.0), \mathrm{KH}_{2} \mathrm{PO}_{4}$ (3.0) with a final $\mathrm{pH}$ of 2.0, adjusted with $6 \mathrm{~N} \mathrm{HCl}$. This medium was used throughout the study.

The experiments were carried out in $250 \mathrm{ml}$ Erlenmeyer flasks in static condition. The $\mathrm{S} / \mathrm{S}$ samples ( $\left.\mathrm{SL}^{*}, \mathrm{SG}^{*}\right)$ were immersed in $T$. thiooxidans media and the control samples (SL, SG) of the same binders without $T$. thiooxidans inoculation in sterile media for 24 hours. On the second day, the control and samples were exposed to fresh sterile media of $\mathrm{pH} 2.0$. The experiments were continued for 11 days in the same condition, by replacing fresh sterile media every day. From the $12^{\text {th }}$ day, both, the S/S samples and S/S controls were exposed to fresh sterile media at $\mathrm{pH}$ 4.0 until 30 days. The leachates were collected periodically and analyzed. The experiments were conducted in triplicates. The data presented are average values.

\section{Analytical}

$\mathrm{pH}$ of the media and leachates was determined using a $\mathrm{pH}$ meter (Systronics, India). Conductivity was measured using conductivity meter (Systronics, India). Analysis of chromium was carried out after acid digestion using Varian Spectra AA 220 Atomic Absorption Spectrophotometer [APHA, AWWA, WEF 1999]. Sulfate, calcium and magnesium were estimated as per Standard methods [APHA, AWWA, WEF 1999]. 


\section{Kinetic analysis}

Two chemical-based shrinking core models, namely a bulk diffusion model and an acid diffusion model [Sophia et al. 2007] were used to analyze the kinetics of microbially-influenced degradation of $\mathrm{S} / \mathrm{S}$ samples.

The bulk diffusion model assumes that contaminant release is due to the difference in concentration between leachant and the bulk concentration within the monolith. It is slow and assumes that the interaction between solid and fluid is non-catalytic. The bulk diffusion model has a limitation that it does not account for the leachant $\mathrm{pH}$ and the observed matrix dissolution in cement during exposure to an acidic environment. These limitations led to the development of shrinking unreacted core (SUC) model to describe leaching mechanisms from solidified/stabilized specimens.

The acid dissolution model is based on the $\mathrm{pH}$ and matrix dissolution, during exposure to acidic environment [Idachaba et al. 2003]. However, the model equations applied in this study for quantitative analysis of kinetic data are Eqs. (1) and (2):

$$
2 / 3 a-(1-a)^{2 / 3}=K_{\mathrm{D}} t \text { (bulk diffusion model) (1) }
$$$$
1-(1-a)^{1 / 3}=K_{\mathrm{A}} t(\text { acid dissolution model) (2) }
$$

Where $a$ represents the fraction of metal leached at time $t$, and $K_{\mathrm{D}}$ and $K_{\mathrm{A}}$ the overall rate constants for the leaching process.

\section{RESULTS AND DISCUSSION}

\section{Effect of microbial degradation on $\mathrm{pH}$ and conductivity}

It is observed from Figure 1 that the $\mathrm{pH}$ of the leachates of control and sample were around 3.0 until the $11^{\text {th }}$ day. From the $12^{\text {th }}$ day onwards $\mathrm{pH}$ of the samples were found to change. The control sample $\mathrm{pH}$ increased due to the alkalinity of cement, while that of the experimental sample decreased due to the release of $\mathrm{H}^{+}$ions by T. thiooxidans. Conductivity values were higher in the experimental S/S leachates exposed to $T$. thiooxidans as compared to the control (Figure 2). Similar results have been reported earlier [Sophia et al. 2007, Idachaba et al. 2003].

\section{Effect of microbial degradation on release of sulfate}

The trend of sulfate in leachates is presented in Figure 3. The data presented corresponds to the net sulfate released from the experimental samples. The sulfate data gives evidence for the microbial grown on the samples. The sulfate release observed was higher in the experimental $\mathrm{S} / \mathrm{S}$ waste than in the control. The reason may be due to oxidation of inorganic sulfur sources such as thiosulfate into sulfuric acid produced during the leaching by $T$. thiooxidans. The cement - lime experimental samples showed the highest cumulative leaching of sulfate $\left(3625 \mathrm{mg} \cdot 1^{-1}\right)$ while; the gypsum containing samples exhibited the lowest leaching for sulfate $\left(2625 \mathrm{mg} \cdot \mathrm{l}^{-1}\right)$. The sulfate release observed was higher in the experimental $\mathrm{S} / \mathrm{S}$ waste than in the control, which may be due to the oxidation of inorganic sulfur sources from the medium into sulfuric acid. The reduction in $\mathrm{pH}$ of the leachates may be due to the formation of the highly corrosive mineral acid.

\section{Effect of microbial degradation on leaching of calcium and magnesium}

One of those major components in cement is calcium. Calcium silicates are formed during curing cement and contribute to the strength of concrete. Tricalcium silicate is responsible for most of the early strength (first 7 days). Dicalcium silicate, which reacts more slowly, contributes only to the strength at later times.

Upon the addition of water, tricalcium silicate rapidly reacts to release calcium ions, hydroxide ions, and a large amount of heat. The reaction slowly continues producing calcium and hydroxide ions until the system becomes saturated. Later the calcium hydroxide starts to crystallize. Simultaneously, calcium silicate hydrate begins to form. Ions precipitate out of solution. This accelerates the reaction of tricalcium silicate conversion to calcium and hydroxide ions. This is found to be an exothermic reaction.

The formation of the calcium hydroxide and calcium silicate hydrate crystals provide „seeds" upon which more calcium silicate hydrate can form. The calcium silicate hydrate crystals grow thicker making it more difficult for water molecules to reach the unhydrated tricalcium silicate. The speed of the reaction is now controlled by the rate at which water molecules diffuse through the calcium silicate hydrate coating. This coating thickens over time causing the production of calcium silicate hydrate to become slower and slower [Conner, Roger 1993]. 


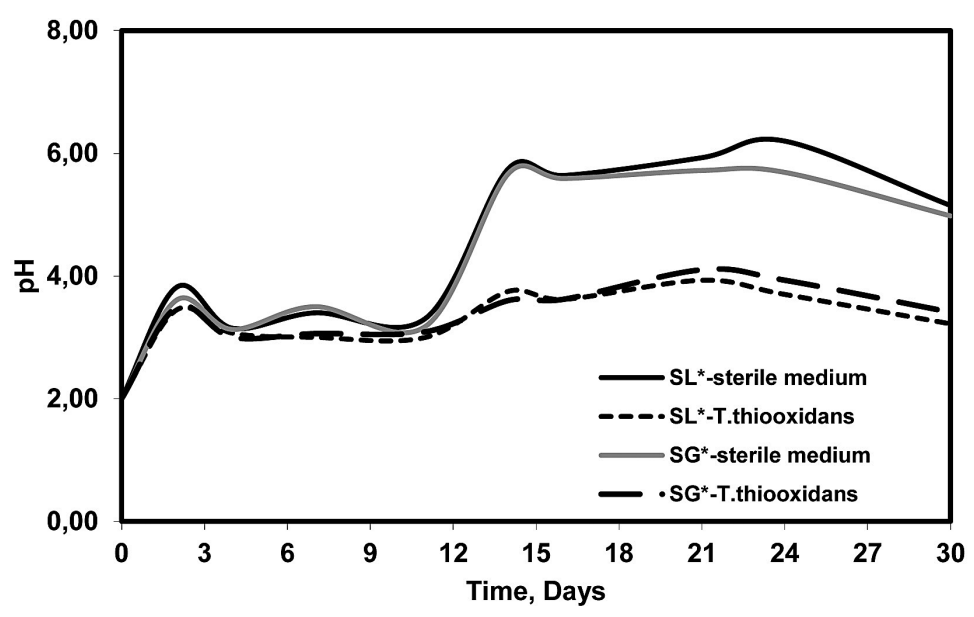

Figure 1. pH profile of microbially leached $\mathrm{S} / \mathrm{S}$ samples

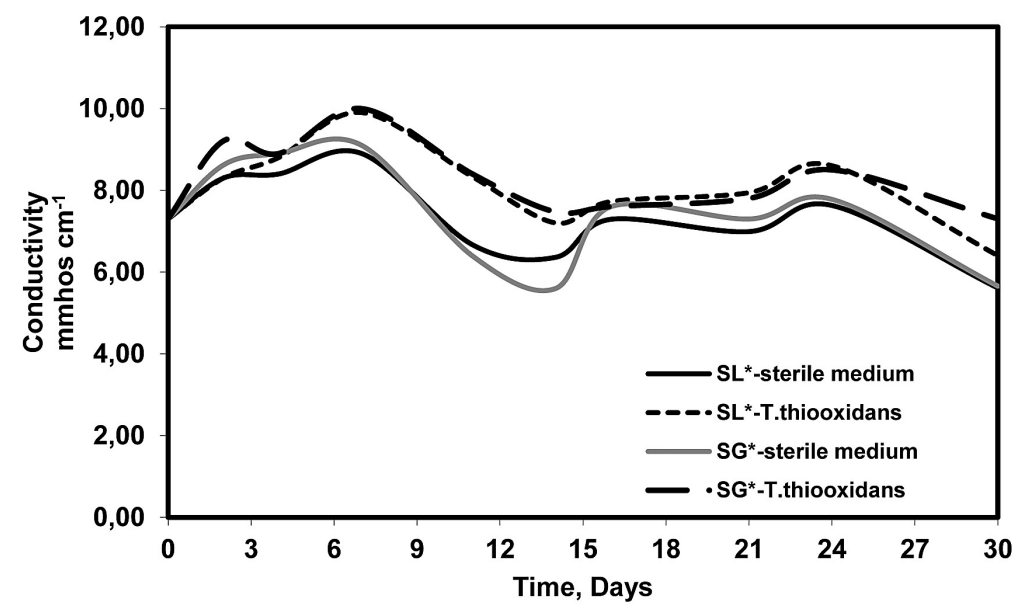

Figure 2. Conductivity profile of microbially leached $\mathrm{S} / \mathrm{S}$ samples

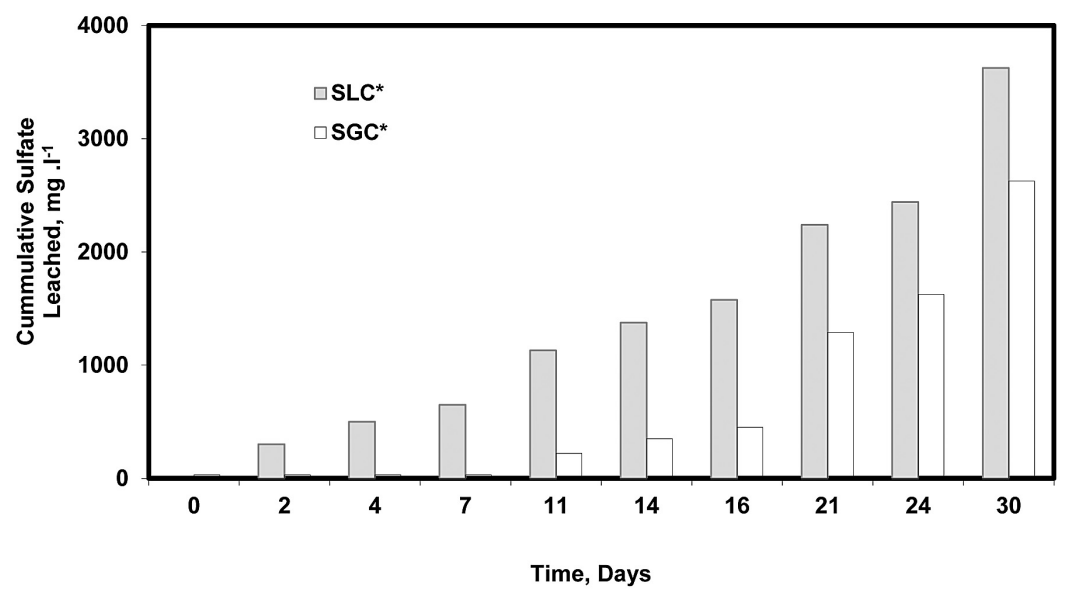

Figure 3. Sulfate profile of microbially leached S/S samples

Figure $4 \mathrm{a}$ and $4 \mathrm{~b}$ presents leaching profile of calcium and magnesium from the experimental samples. Leaching of calcium and magnesium was higher in the $\mathrm{S} / \mathrm{S}$ sample exposed to $T$. thiooxidans as compared to the sterile controls. This is because T. thiooxidans is known to be involved in the degrada- tion of cement-based materials like concrete, through production of mineral acids [Diercks et al. 1991]. The mineral acids produced such as sulfuric acid are found to react with compounds of calcium and magnesium in cement resulting in the formation of insoluble salts of calcium and magnesium such as calcium sul- 


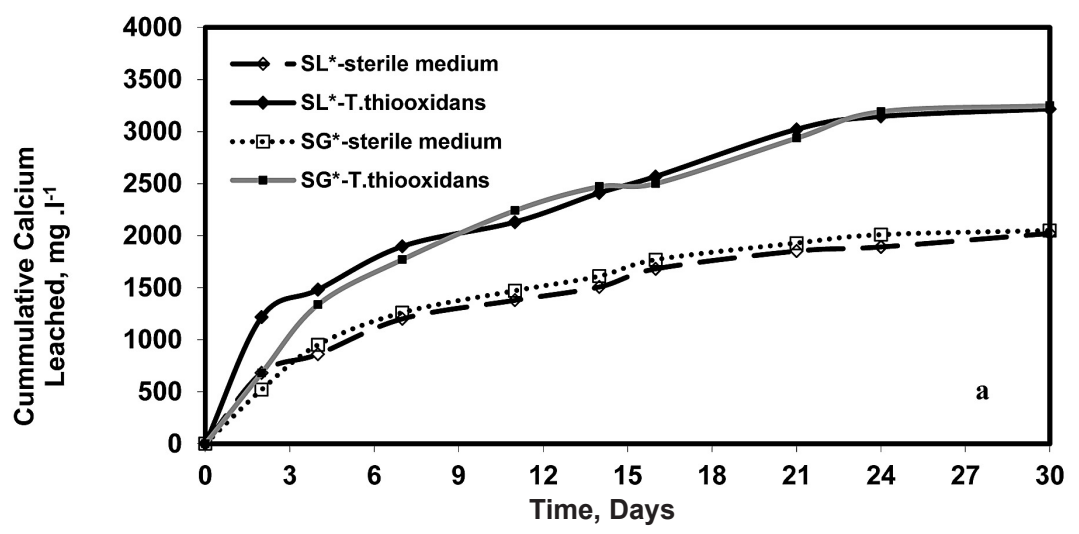

Figure 4a. Calcium profile of microbially leached S/S samples

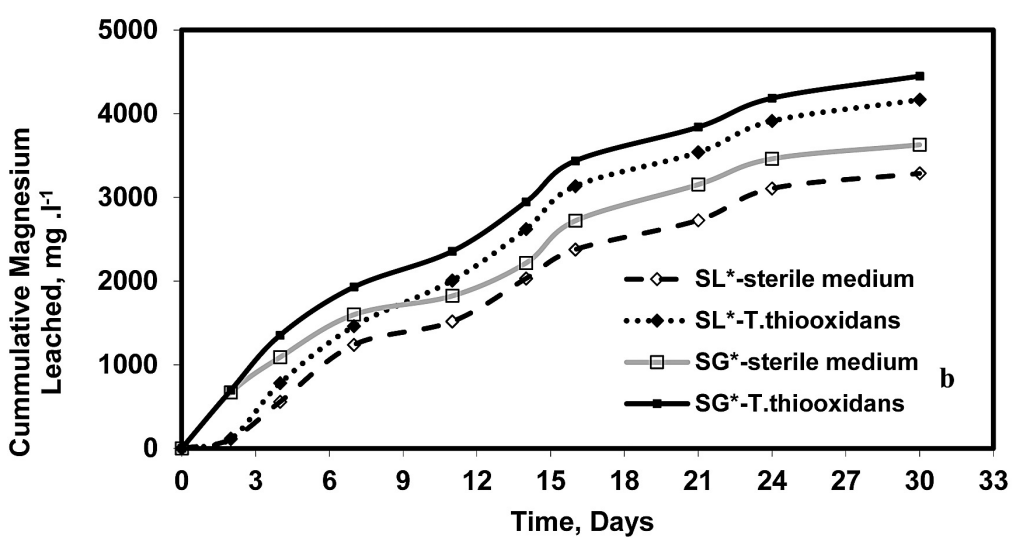

Figure 4b. Magnesium profile of microbially leached S/S samples

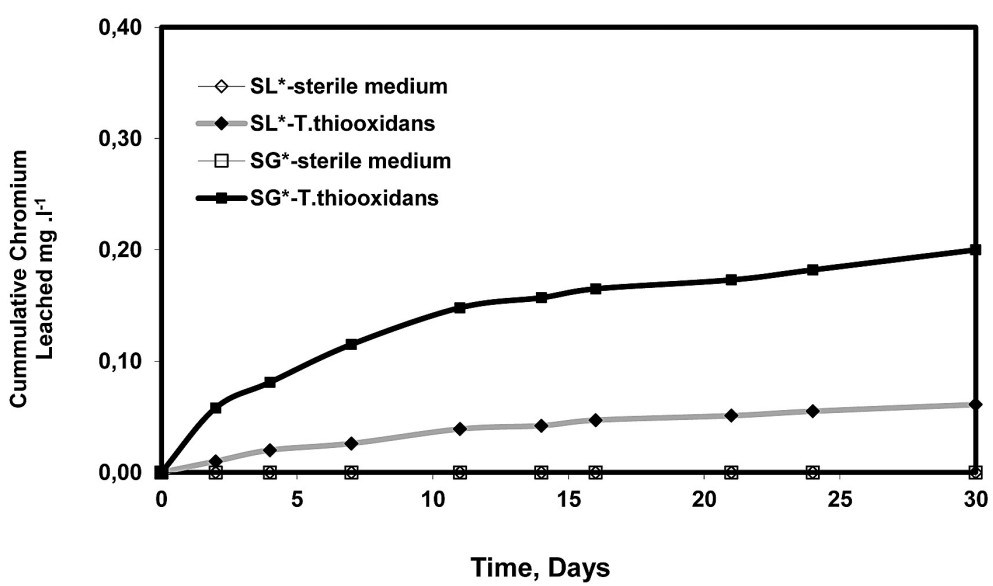

Figure 5. Chromium profile of microbially leached S/S samples

fate and magnesium sulfate [Sand, Bock 1988]. It is reported [Sand 1987] that concrete in its main structure is composed of calcium oxides, hydroxides, and carbonates. These compounds can react with acids:

$$
\begin{gathered}
\mathrm{Ca}(\mathrm{OH})_{2}+\mathrm{H}_{2} \mathrm{SO}_{4}^{-} \\
\mathrm{CaSO}_{4}+2 \mathrm{H}_{2} 0
\end{gathered}
$$

The reaction product is gypsum. The calcium loss diminishes the resistance of the solidified sample.

\section{Effect of microbial degradation on leaching of chromium}

The leaching of chromium from the experimental samples LC, LC*, GC \& GC* using the biofilm formation method are presented in Figure 5. LC* and GC* leached out 4.54 and $14.3 \mathrm{mg} / \mathrm{g}$ of cumulative chromium respectively after 30 days of exposure. The corresponding concentration of chromium in the leachate was 0.061 and $0.22 \mathrm{mg} \cdot \mathrm{l}^{-1}$, respectively. The chromium in the 


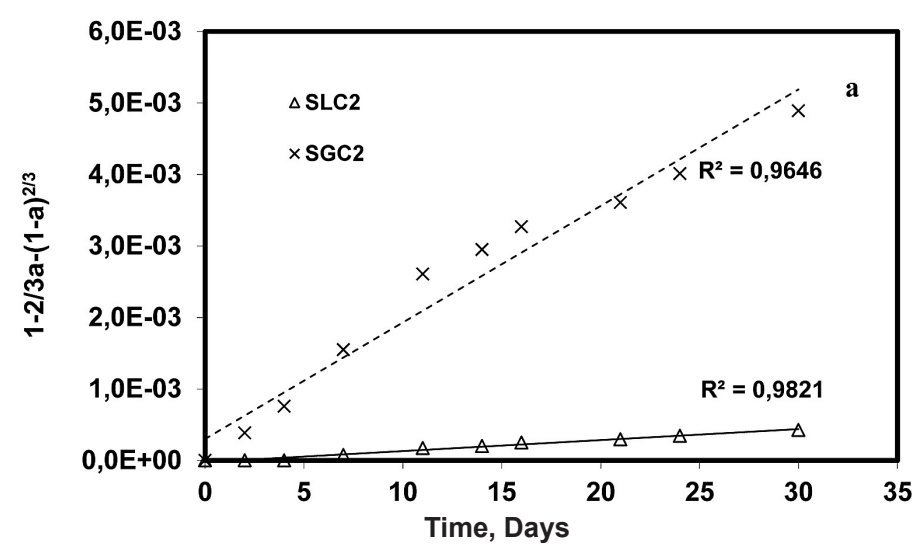

Figure 6a. Kinetics of microbial degradation of S/S samples by bulk diffusion model

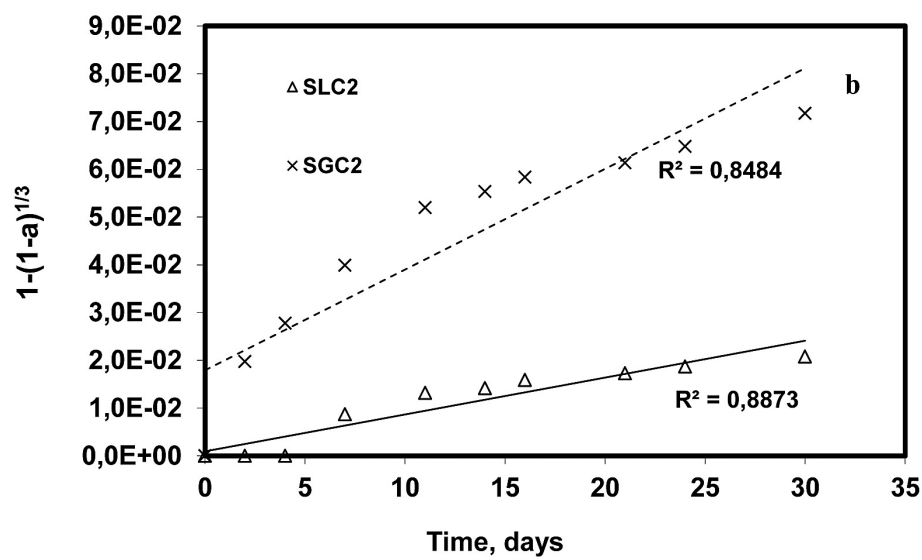

Figure 6b. Kinetics of microbial degradation of S/S samples by acid dissolution model

leachate was lower than the toxicity characteristic leaching procedure (TCLP), regulatory limit $\left(5 \mathrm{mg} \cdot \mathrm{l}^{-1}\right)$.

Chromium was not detected in effluent samples obtained from the sterile control within the same period. These results show that the $\mathrm{S} / \mathrm{S}$ process effectively restricted the leaching of chromium by microbial induced degradation. It was also noticed that replacement of cement by $10 \%$ lime in ' $L C$ ' could restrict leaching of chromium more efficiently. This phenomenon may be due to the high $\mathrm{pH}$ of lime leachates.

\section{Kinetic analysis using shrinking core models}

Results of comparative kinetic analysis of chromium leaching data using acid dissolution and bulk diffusion kinetic model equations are presented in Figure 6. It is evident from the figure that the analysis of data using the bulk diffusion model (Figure 6a) gives a better linear correlation than the analysis using the acid dissolution approach (Figure 6b). While a straight line going through the origin with correlation of about 0.96 for $\mathrm{GC}^{*}$ and 0.98 for $\mathrm{LC}^{*}$ for the bulk diffusion model. The distribution of the data points using the acid dissolution approach does not allow a statistically reasonable straight line. The best straight line through the data points gives a substantially low correlation of 0.887 for LC*.

The results suggest that microbial degradation follows closely the bulk diffusion mechanism of waste form degradation. Thus, the kinetic model equation based on the bulk diffusion model can be used for quantitative kinetic analysis of data obtained from microbial degradation experiments [Sophia, Swaminathan 2007]. A study also suggests that microbial degradation of waste forms may involve additional mechanisms than mere production of acids [Idachaba et al. 2004].

\section{CONCLUSIONS}

Microbial leaching on S/S waste made using binders such as cement, lime and gypsum was studied. Increase in sulfate production proved an evidence for microbial growth by formation of biofilm on $\mathrm{S} / \mathrm{S}$ waste. Oxidation of inorganic sulfur into sulfuric acid may be responsible for 
the reduction in $\mathrm{pH}$ in the $\mathrm{S} / \mathrm{S}$ waste. Chromium was well fixed in the matrix as indicated by the low concentration of chromium in the leachates. The results also showed significant differences in chromium binding in different $\mathrm{S} / \mathrm{S}$ samples. Kinetic analysis of the microbial degradation of $\mathrm{S} / \mathrm{S}$ samples was performed using shrinking core models. Model equations used in this study was acid dissolution or shrinking un-reacted core (SUC) model, and bulk diffusion model. The major driving force in the microbial induced leaching of metals from $\mathrm{S} / \mathrm{S}$ waste appears to be bulk diffusion as a result of the concentration gradient, rather than acidity.

\section{Acknowledgements}

The authors wish to extend their thanks to the Director, CSIR-NEERI Nagpur, permitting to do this research work at NEERI, Chennai Zonal Lab.

\section{REFERENCES}

1. Sophia A.C., Swaminathan K. 2005. Assessment of the mechanical stability and chemical leachability of immobilized electroplating waste. Chemosphere, 58, 75-82.

2. Conner J.R. 1990. Chemical fixation and solidification of hazardous wastes. Van Nostrand Reinhold. New York.

3. Rossetti V.A., Di Palma L., Medici F. 2002. Assessment of the leaching of metallic elements in the technology of solidification in aqueous solution. Waste Management, 22(6), 605-610.

4. Chong Y.R., Seong K.K., Chang E.K. 2000. Investigation of the stability of hardened slag paste for the stabilization/solidification of wastes containing heavy metal ions. J. Hazardous Materials, B(73), 255-267.

5. Tsivilis S., Batis G., Chaniotakis E., Grigoriadis Gr., Theodossis D. 2000. Properties and behavior of limestone cement concrete and mortar. Cement Concrete Res, 30, 1679-1683.

6. Poon C.S., Chen Z.Q. 1999. Comparison of the characteristics of flow through and flow around leaching tests of solidified heavy metal waste. Chemosphere, 38(3), 663-680.

7. Wang S., Vipulanandan C. 2000. Solidification/stabilization of $\mathrm{Cr}(\mathrm{VI})$ with cement Leachability and XRD analyses. Cement Concrete Res, 30, 385-389.
8. Chan Y.M., Agamuthu P., Mahalingam R. 2000. Solidification and stabilization of asbestos waste from an automobile brake manufacturing facilityusing cement. J. Hazardous Materials, 77(1-3), 209-226.

9. Sophia A.C., Swaminathan K., Sandhya S. 2007. Microbially-influenced degradation of solidified/ stabilized metal waste. Bioresource Technology, 98, 2562-2567.

10. Idachaba M.A., Nyavor K., Egiebor N.O. 2002. Evaluation of microbial stability of simulated solid and liquid waste forms using a refined biofilm formation method. J. Hazardous Materials, B(90), 279-295.

11. Idachaba M.A., Nyavor K., Egiebor N.O. 2003. Kinetic analysis of data obtained from studies on microbial degradation of cement waste forms, using shrinking core models. J. Hazardous Materials, B(99), 57-69.

12. Mori T., Nonaka T., Tazaki K., Koga M., Hikosaka Y., Noda S. 1992. Interactions of nutrients, moisture and $\mathrm{pH}$ on microbial corrosion of concrete sewer pipes. Water Res, 26(1), 29-37.

13. Parker C.D. 1945. The isolation of a species of bacterium associated with the corrosion of concrete exposed to atmospheres containing hydrogen sulfide. Australian J. Experi. Biolog. Medi. Sci. 23, 81-90.

14. APHA. 1999. Standard Methods for the Examination of Water and Wastewater, $20^{\text {th }}$ edition, American Public Health Association, American Water Works Association, AWWA, Water Environment Federation, WEF, Washington, D.C. U.S.A.

15. Conner J.R., Roger D.S. 1993. Chemistry and Microstructure of Solidified Waste Forms. Lewis Publishers, Ed. London.

16. Diercks M., Sand W., Bock E. 1991. Microbial corrosion of concrete. Experientia, 47, 514-516.

17. Sand W., Bock E. 1988. Biogenic sulphuric acid attack in sewage systems. In: Houghton, D R Smith, R N Eggins, H.O.W. Ed. Biodeterioration, 7. Elsevier Applied Sci-ence, London and New York.

18. Sand W. 1987. Importance of Hydrogen Sulfide, Thiosulfate, and Methylmercaptan for Growth of Thiobacilli during Simulation of Concrete Corrosion. Appl. Environ. Microbiol, 53(7), 1645-1648.

19. Idachaba M.A., Nyavor K., Egiebor N.O. 2004. Leaching of chromium from cement waste forms via predominantly biological mechanism. Adv. Environ. Res, 8, 483-491. 